\title{
An Asymmetric [3+2] Cycloaddition/Ring-Expansion Sequence Towards Lysergic Acid
}<smiles></smiles>

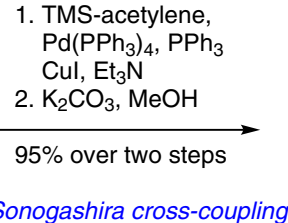<smiles>C#Cc1cccc2[nH]cc(CCOCCOCCOCCOCCO)c12</smiles>
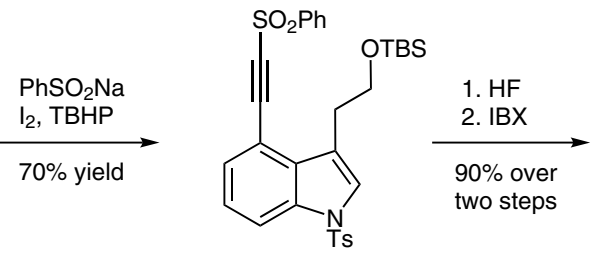<smiles></smiles><smiles>CC12CCC(N(C(=O)CN)C(S(C)(=O)=O)C1)C2(C)C</smiles>

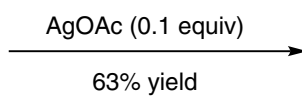

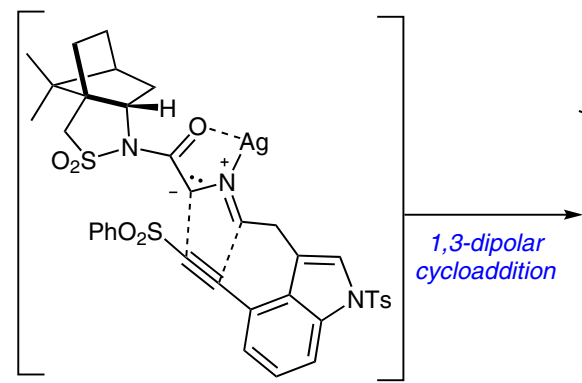

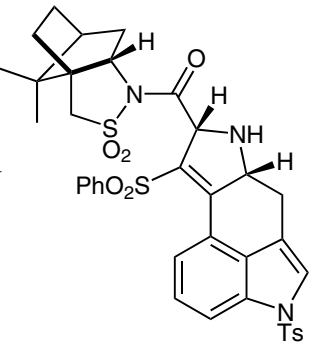

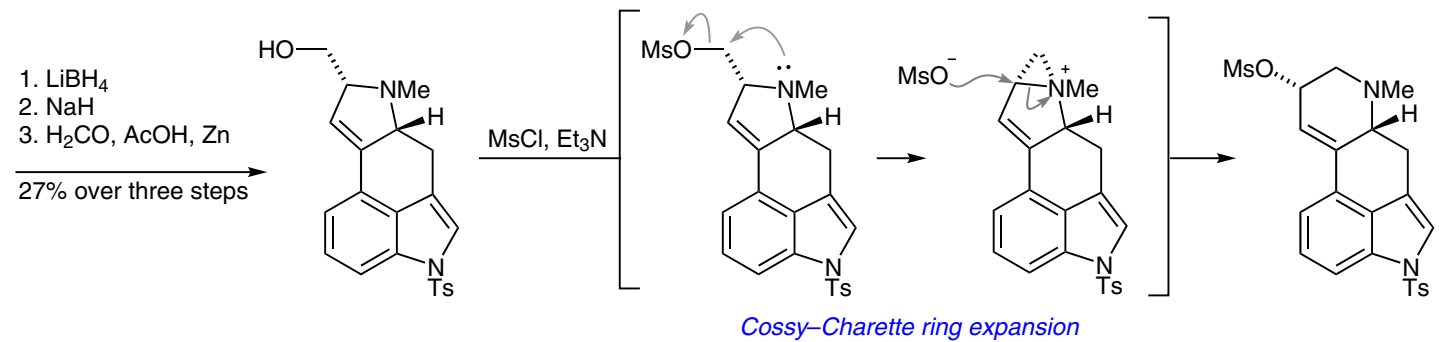

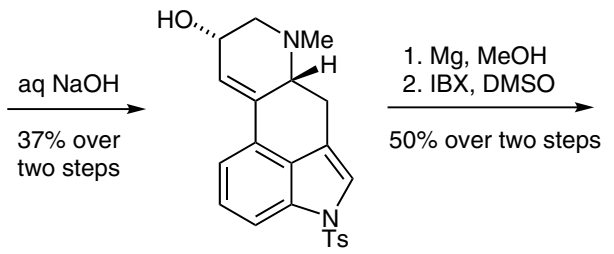

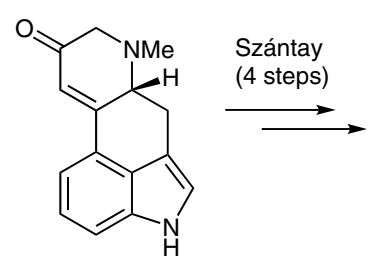<smiles>CC1(C)Cc2c[nH]c3cccc(c23)C1=CC(=O)O</smiles>

(+)-Lysergic acid

Significance: Amide derivatives of lysergic acid have been investigated for the treatment of various neurological disorders. While many syntheses of lysergic acid itself have been disclosed previously, Rathnayake and Garner describe a new strategy to afford the enantiopure piperidine core.

\section{Category}

Chemistry in

Medicine and Biology

\section{Key words}

1,3-dipolar cycloaddition

Oppolzer's auxiliary

Cossy-Charette ring expansion
Comment: Using Oppolzer's camphorsultam auxiliary, an intramolecular 1,3-dipolar cycloaddition of the in situ generated azomethine ylide and the alkyne established an enantiopure dihydropyrrole. A subsequent aziridinium-mediated ring expansion then afforded the piperidine core of lysergic acid. 